\title{
Clause Intertwining and Word Order in Ancient Greek ${ }^{*}$
}

\author{
Rutger J. Allan \\ VU University Amsterdam \\ rj.allan@let.vu.nl
}

\begin{abstract}
In Ancient Greek complex sentences consisting of a main and complement clause, constituents which semantically and syntactically belong to the complement clause can be placed in a position preceding or interrupting the main clause. This phenomenon is referred to as clause or sentence intertwining. This paper examines the pragmatic factors involved in the preposing of contituents in sentences containing an infinitival complement clause. It will be argued that the specific pragmatic function of the preposed constituents is Theme (left dislocation), new/contrastive topic or narrow focus. Preposing can be analyzed as a device to pragmatically highlight the involved constituents. The paper also addresses the position of new, contrastive and given topics and of adverbs and clauses with Setting function.
\end{abstract}

Keywords

word order; clause intertwining; information structure; topic; focus

\section{Introduction}

In Ancient Greek, complex clause constructions consisting of a main and an infinite complement clause exhibit a wide variety of word order patterns. A complement clause may follow the main clause (1) but it can also appear preceding the main clause (2). Moreover, the two clauses can also be intertwined in various ways. In the case of clause intertwining, one or more constituents semantically and syntactically belonging to the complement verb are placed in a position preceding (3) or interrupting (4) the main clause.

\footnotetext{
*) I wish to thank the editors of this issue and three anonymous reviewers for their constructive comments on an earlier version of this paper.

(C) Koninklijke Brill NV, Leiden, 2012

DOI: $10.1163 / 156658412 X 649733$
} 
(1) Main Clause-Complement Clause

(2) Complement-Main

(3) Complement-Main-Complement

(4) Main-Complement-Main-Complement

Examples of these orderings are:

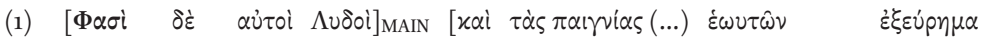
they.say PTC self Lydians also the games of.themselves invention

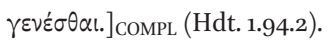
become.INF ${ }^{1}$

And the Lydians themselves say that also the games (...) have been their invention.

(2) $[\tau 0 \hat{\tau} \tau 0 \mu \dot{v} \nu \quad \delta \dot{\eta} \quad \alpha \dot{\pi} 0 \delta \varepsilon \delta \varepsilon \hat{\chi} \chi \theta \alpha]_{\text {COMPL }} \quad[\varphi \hat{\omega} \mu \varepsilon v ;]_{\text {MAIN }}(P l . P h d .105 \mathrm{e})$ that PTC PTC prove.PRF.PASS.INF say.SBJV.1.PL

- Shall we then say that this is proved?

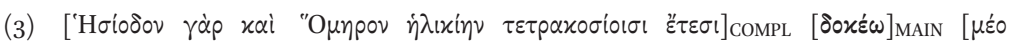
Hesiodus for and Homer period 400 years I.believe than.me

$\pi \rho \varepsilon \sigma \beta u \tau \varepsilon ́ p o u \varsigma ~ \gamma \varepsilon v \varepsilon ́ \sigma \theta \alpha l]_{\text {COMPL }}($ Hdt. 2.53.2) older be.born.INF

For I believe that Hesiod and Homer lived 400 years earlier than me.

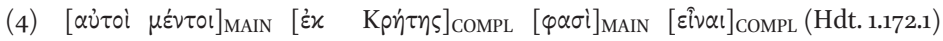
self but from Crete they.say be.INF

But they say themselves that they came from Crete.

The question presents itself as to how we can account for this variation in interclausal word order. The main aim of this paper will be to make a first attempt to explore this relatively uncharted area of Greek word order research. The focus will mainly be on the phenomenon of clause intertwining as exemplified by (3) and (4). Clause intertwining can be considered marked constituent orderings because they violate the Principle of Domain Integrity which is a general constituent ordering principle which states that '[c] onstituents prefer to remain within their proper domain; domains prefer not to be interrupted by constituents from other domains' (Dik 1997: I.402). The reason for the violation of this principle, I will argue, is to pragmatically highlight the constituents preceding the main verb. The ordering of type (2), furthermore, can be accounted for by the same discourse-pragmatic factors.

In the last two decades, the study of Ancient Greek constituent order has made significant progress thanks to two seminal studies by Helma Dik 1995 and Dejan Matić 2003. Dik and Matić have demonstrated clearly that the problem

1) The abbreviation PTC stands for particle. 
of Greek word order can be fruitfully approached from a discourse pragmatic perspective: clausal word order turns out to be determined primarily by the particular pragmatic function of the constituent at issue. The word order models of Dik and Matić take the clause as the basic unit of description. This means that their models are not designed to cover word order patterns of complex sentences. Nonetheless, as will become clear later, there is much to be learned from these models also in the analysis of complex sentences. Since a detailed discussion of the clausal word order models of Dik and Matić is beyond the scope of this paper, I will focus on those aspects of their models that are of direct relevance to the analysis of word order in complex sentences. But let us first consider what type of sentences will be the subject of our investigation.

The sentences I am concerned with are those of which the main verb is a complement-taking verb. Complement-taking verbs can be modal verbs (e.g.

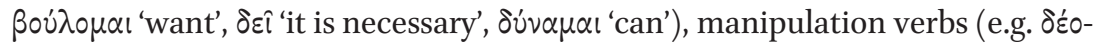

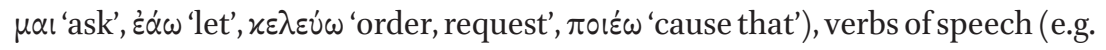
$\lambda \varepsilon^{\prime} \gamma \omega$ 'say', $\varphi \eta \mu i$ 'say'), or mental process verbs (perception, cognition or emo-

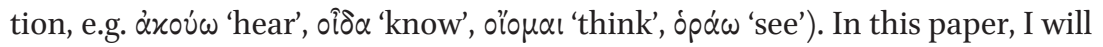
focus on those verbs that take an infinitival complement clause (see KühnerGerth 1898: II.24-33, Smyth-Messing 1956: 443-444). Participial and finite complement clauses will be left out of account. As is known, the subject of the infinitive clause appears in the accusative case if it is different from the main clause subject (accusativus cum infinitivo).

Before I move on to an analysis of the corpus data, it is important to define the terms which will be used. In general, the terminology is derived from Simon Dik's Functional Grammar, more particularly, from Dik 1997. The following terms will be used: Theme, Setting, new topic, constrastive topic, given topic, narrow focus and broad focus. In Functional Grammar, the term Theme is used to refer to a separate (left detached) intonation unit preceding the main clause which refers to an entity 'with regard to which the following clause is going to present some relevant information' (Dik 1997: 389). ${ }^{2}$ An English example is

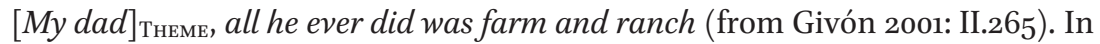
Ancient Greek, Theme constructions typically serve to promote the referent from a relatively peripheral ('semiactive') discourse status into the very centre of attention (see Allan, Forthc.). Themes are typically resumed topics, i.e. they are used to bring back topical referents into the discourse which have been

2) Note that the notion of Theme in Dik's Functional Grammar is different from that of the Prague School (e.g. Firbas 1964) and of Halliday (e.g. 1967). 
out of the focus of attention for a while. Themes can also be subtopics: topics which are inferentially related (on the basis of a cognitive frame/schema) to an earlier given topic. ${ }^{3}$

Settings are adverbial clauses preceding the (main) clause which specify time, location and/or other circumstantial state of affairs (Dik 1997: II.397). An

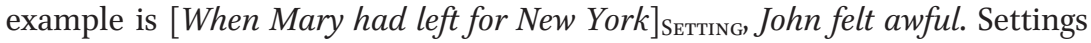
have a grounding function with respect to the subsequent main clause in that they specify time, location and/or other circumstantial state of affairs. Apart from their link to the subsequent discourse, they typically also show signs of a pragmatic connection with the preceding discourse. In this way, they constitute a coherence bridge between the preceding and the following discourse. In Ancient Greek, Settings are typically subordinate finite or participial (conjunct participle or absolute genitive) clauses (Dik 2007: $36-37$ ).

A topic expression refers to an entity which is assumed by the speaker to be part of (or inferable from) the information shared by the speaker and addressee. The topic is a 'matter of current interest which a statement is about and with respect to which a proposition is to be interpreted as relevant' (Lambrecht 1994). New topics are entities which are newly introduced into the discourse (Dik, 1997: II.314-318). In Ancient Greek, clause-initial new topics tend to be identifiable to the addressee on the basis of general knowledge shared by the speaker/narrator and addressee. So even though they are new to the discourse they are usually not brand-new to the discourse participants. Contrastive topics are topics referring to an entity which is a member selected from of a limited set of candidates belonging to the same semantic class (Lambrecht 1994: 291-295, Givón 2001: II.262), e.g. I saw Socrates and Plato yesterday. [Socrates] CONTrTopic

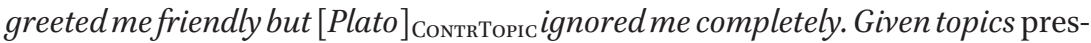
ent entities which are supposed to be highly accessible to the addressee (Dik, 1997: II.294). They refer to entities which are presumed to be in the centre of the addressees consciousness, without serious competition from alternative topical referents (as opposed to contrastive topics). ${ }^{4}$ Typically, the referent of a given topic has already been mentioned in the preceding sentence. For example, I saw Socrates yesterday. $[\mathrm{He}]_{\mathrm{GIVEN}}$ TopIC was very friendly to me.

\footnotetext{
3) For the notion of resumed topic and subtopic, see Dik 1997: I.323-326. Theme constructions are also referred to as left detachment (e.g. Lambrecht 1994) or left dislocation (e.g. Givón 2001). The form and function of Theme constructions in Ancient Greek have been discussed by Bakker 1990, Ruijgh 1990, Slings 1992, 1997, 2002, H. Dik 1995, 2007: 34-36, Bertrand 2010: 276-286 and Allan, Forthc.

4) In the terminology of Chafe, given topics have an active status in the addressee's consciousness. For the three-way distinction between active, semiactive and inactive information status, see Chafe 1994.
} 
The focus of a sentence is that piece of information 'which is relatively the most important or salient in the given communicative setting, and considered by $\mathrm{S}$ [peaker] to be most essential for $\mathrm{A}$ [ddressee] to integrate into his pragmatic information' (Dik 1997: I.326). The distinction between narrow and broad focus constructions has been introduced into the study of Ancient Greek word order by Matić 2003. In a narrow focus construction, the focus is carried by one single constituent, e.g.-Who did you see yesterday? - I saw [Socrates $]_{\text {Narrow Foc. In a }}$ broad focus construction, the focus domain comprises the verb plus optionally one or more additional focal constituents, e.g.-What did you do yesterday? - I [read Plato's 'Symposium' $]_{\text {Broad Foc. }}{ }^{5}$

In this paper, I will argue that the constituent order of a complex sentence can be described by means of the following schema:

(5) Word order schema complex sentence: ${ }^{6}$

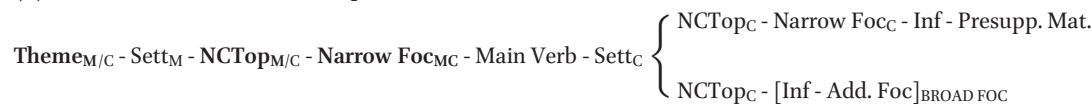

The word order schema of complex sentences could be characterized as a 'blend' between two clausal schemas. In first position, we find the Theme (left dislocated topic), which is either linked to the main clause (M) or to the complement $(\mathrm{C})$. The Theme can be followed by a Setting (frame-setting adverbial clause) which is associated with the main clause. ${ }^{7}$ Next, a new or contrastive topic (NCTop) may be placed. ${ }^{8}$ The slot preceding the main verb is reserved for the primary narrow focus constituent, either belonging to the main or to the complement clause. ${ }^{9}$ The main verb can be followed by a Setting clause

\footnotetext{
5) Narrow focus is equivalent to Lambrecht's argument focus, while broad focus comprises Lambrecht's predicate focus and sentence focus (Lambrecht 1994: 222-238).

6) For the sake of clarity I left out of the schema the positions of prepositive and postpositive words, setting adverbs, given topics. Prepositive and postpositive words are subject to ordering rules entirely different from those of 'mobile' words (Dover 1960, Marshall 1987, Goldstein 2010) and are therefore beyond the scope of this paper. Setting adverbs tend to occur in the absolute clause-initial position; given topics can be located in the position immediately following the main or after the complement verb. These types of constituents will be dealt with later.

7) For Themes and Settings in Greek, see also Dik 2007: 34-38 and Allan, Forthc.

8) In Allan, Forthc. I argue that there are different topic types which occur at different positions in the structure of the clause. Clause-initial topics are new or contrastive topics, Themes (i.e. left dislocated extra-clausal topics) are resumed topics or subtopics. Postverbal topics are given (i.e. continuous) topics. Given topics are not represented in the word order schema for the sake of clarity. I will go into these different types of topic expressions in more detail in sections 2, 4 and 6. 9) This part of the schema is based on Helma Dik's general clause pattern Setting-TopicFocus-Verb-Remainder (Dik 2007: 38). Dik's Topic is in my schema specified as new or contrastive topic. Following Matić 2003, I assume that given (continuous) topics (not represented in the schema) are placed in the position immediately following the verb. I also follow Matić in
} 
that is associated with the complement clause. Next, the infinitival complement clause follows. In first position a new or constrastive topic may be placed. Following the NCTopic we find either a narrow focus or a broad focus construction. It goes without saying that, in actual discourse, many slots in the schema remain unfilled.

Probably the most conspicuous feature of the schema is the possibility of placing Themes, topics and focus constituents which syntactically belong to the complement clause (written boldface in schema (5) above) in front of the main verb. Preposing constituents in this way is a strategy to highlight them pragmatically (Dik 1997: II.341-342). ${ }^{10}$ The preverbal topic and focus positions of the main verb are 'lent' to constituents of the complement clause in order to increase their discourse prominence. Preposing results in a pragmatically marked word order due to the violation of the Principle of Domain Integrity. Instead of being placed within the complement clause domain to which it semantically and syntactically belongs, it is 'displaced' into the domain of the main clause. ${ }^{11}$ In the same way, (narrow) foci belonging to the complement clause can end up in a position preceding the main verb.

The increased pragmatic saliency of the preposed elements can, in my view, be explained by the cooperation of two general cognitive principles. The first concerns the principle of 'task urgency' as formulated by Givón, which states 'attend first to the most urgent task' (Givón 1983: 20). The second principle regards the difference in cognitive salience between main and subordinate clauses. Main clauses are often considered to be cognitively foregrounded, that is, in the centre of attention, while subordinate clauses tend to contain backgrounded material (see e.g. recently Wårvik 2004).

To get an impression of the relative markedness of various word order patterns, it is illustrative to examine some statistical data drawn from Herodotus and Plato. ${ }^{12}$

regarding Dik's Focus as a narrow focus. For the distinction between narrow and broad focus, see below.

10) Related constructions which involve the 'displacement' of a constituent are prolepsis and hyperbaton. For a functional-pragmatic account of prolepsis in Ancient Greek, see Panhuis 1984, Chanet 1988 and Slings 1992. Hyperbaton has been treated by Devine \& Stephens 2000 and Bertrand 2010. Hyperbaton shows a remarkable affinity with preposing in intertwined clauses in that both topical and focal elements can be preposed.

11) The phenomenon involving the placement of a (part of a) constituent outside its proper domain is often referred to by the term 'displacement'. For a general functional account of these phenomena, I refer to Dik 1997: I.436-439, II.339-351.

12) The corpus consists of all sentences containing the main verbs $\beta \circ v^{\prime} \lambda \circ \mu \alpha$ l, $\delta \circ \chi \varepsilon \dot{\varepsilon} \omega, \chi \varepsilon \lambda \varepsilon v^{\prime} \omega$, oij $\mu \alpha$ l and $\varphi \eta \mu i$ construed with an infinitival complement clause in the 1st book of Herodotus' Histories and in Plato's Symposion. 
(6) Order of main verb and infinitive

Main verb-Inf 194

Inf-Main verb 20

Total: $\quad 214$

The complement-taking verbs overwhelmingly precedes their complement infinitives. This is paralleled by the general tendency in Ancient Greek for auxiliaries (e.g. $\delta \varepsilon \hat{\imath}, \mu \varepsilon \hat{\imath} \lambda \omega, \chi \rho \eta \dot{n})$ to precede their infinitive complements. The markedness of the preposed infinitive shows in the strongly asymmetrical distribution. I will go into the factors explaining preposed infinitives in section (4).

(7) Preposed vs. non-preposed topics and foci New/Contrastive Topic Narrow Focus

$\begin{array}{lll}\text { Preposed } & 13(42 \%) & 44(34 \%) \\ \text { Non-preposed } & \mathbf{1 8}(58 \%) & \mathbf{8 5}(66 \%) \\ \text { Total: } & 31(100 \%) & 129(100 \%)\end{array}$

Preposed contrastive/new topics (13 instances) occur less frequently than nonpreposed topics $(18 \times)$. The markedness of the preposed position of topics shows in the lower frequency of occurrence: $34 \%$ preposed vs. $66 \%$ non-preposed. In the rest of my paper, I will discuss the following issues: first, I will go into the pragmatic factors explaining the preposed position of topics (section 2) and focus constituents (section 3). Next, the issue of preposed infinitives will be addressed (section 4). Third, the position of extra-clausal constituents (Themes and Settings) will be discussed (section 5 ). In section (6), a short note will be dedicated to the position of frame-setting adverbs and given topics. Section (7), finally, the phenomenon of clause intertwining is analyzed as a form of raising.

\section{Preposed Topic}

A topic expression refers to an entity which is assumed by the speaker to be part of (or inferable from) the information shared by the speaker and addressee. It is a 'matter of current interest which a statement is about and with respect to which a proposition is to be interpreted as relevant' (Lambrecht 1994). What is the motivation for placing topics within the main clause domain instead of in domain of the complement clause? In the following example, both topic and focus belonging to the complement clause are preposed..$^{13}$

\footnotetext{
13) In the examples throughout this paper, the main (embedding) verb is in bold-face and the constituent under discussion is underscored.
} 


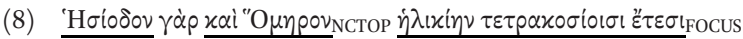

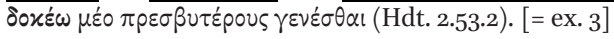

Hesiod and Homer are newly introduced in the discourse (new topic) and they remain the central discourse topic in the following discourse unit. Hesiod and Homer are part of the general cultural knowledge shared by Herodotus and his audience. So even though Hesiod and Homer have not been mentioned previously in the discourse (i.e., they are inactive referents), they are easily identifiable to the addressee and therefore perfectly acceptable as topic of the sentence. ${ }^{14}$ Herodotus' aim here is to argue against the common opinion by stating that Hesiod and Homer lived no more than 400 years before his own

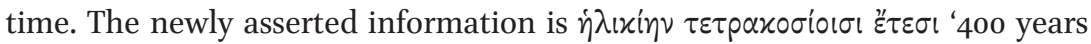

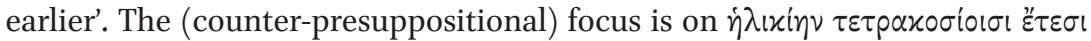
which is placed in preposed position. The comparative adjective $\pi \rho \varepsilon \sigma \beta u \tau \varepsilon$ pov is following the main verb and thus presented as presupposed information: the fact that Hesiod and Homer are older than Herodotus is hardly controversial. The clitic pronoun $\mu \varepsilon$ o is attached to the main verb. ${ }^{15}$

Examples like (8) are quite rare. In most cases, either the topic or the focus constituent is preposed. A factor explaining the preposing of the topic appears to be the degree of discourse prominence of the topic referent. Preposed topics often refer to those discourse topics that are central to the discourse, whereas those referring to discourse topics of secondary significance tend not to be preposed. ${ }^{16}$ For example,

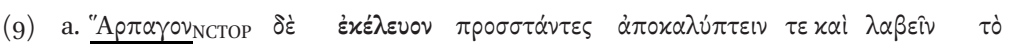
Harpagos.ACC PTC they.told having.stood open.INF and take.INF what

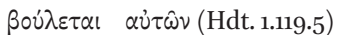

he.wants of.them

And they stood before Harpagus and told him to open it and take what he liked. ${ }^{17}$

\footnotetext{
14) For the Topic Acceptability Scale indicating the correlation between the activation state of the topic referent and the pragmatic acceptability of the sentence, see Lambrecht 1994: 165.

15) The position following the main verb- not in second 'Wackernagel's' position! (Wackernagel 1892) - is, in fact, the most typical position of pronominal postpositives in my corpus data (even if they are arguments of the complement infinitive). The increasing diachronic tendency for postpositives to follow the verb is also noted by Marshall 1987: 15.

16) Discourse topics are 'those entities about which a certain discourse imparts information' (Dik 1997: I.314). A discourse may have multiple discourse topics, some more central to the discourse than others. Constituents that are marked as more topical tend to have been topical in the preceding discourse and to persist longer in the subsequent discourse (see Givón 2001, 1, 198 and Allan, Forthc).

17) Translations of Herodotus (sometimes adapted) are from Godley (1920).
} 


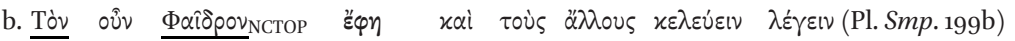
ART PRT Phaedrus.ACC he.said and the others urge.INF speak.INF Then he [Aristodemus] said that Phaedrus and the others urged him to speak (...). ${ }^{18}$

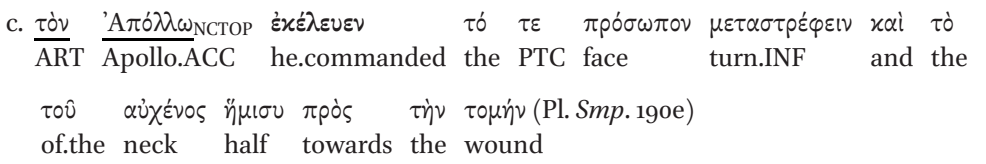

He [Zeus] commanded Apollo to turn its face and half its neck towards the wound.

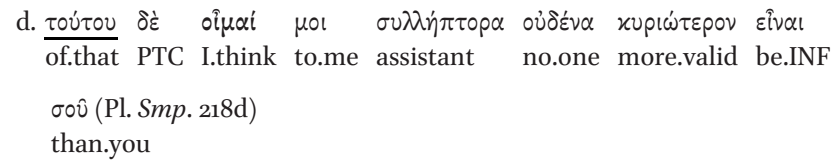

No one can help me more than you to reach that aim.

The subject accusative of the infinitive clause (accusative plus infinitive) is typically the topic of the complement clause. Harpagus in (9a) is obviously a major protagonist in the episode in which his son is killed, cooked and served to him by Astyages. Phaedrus (in b) is one of the participants of the symposium. Apollo is newly introduced in the discourse in (c) and he will continue to play a central role in the subsequent part of Aristophanes' speech as he shapes the human body. In (d), the preposed topic is an anaphoric pronoun. Since they serve as a cohesive link with the preceding context, anaphoric pronouns naturally favor the initial position in the sentence. ${ }^{19}$

Non-preposed new or contrastive topics (i.e. topic constituents placed within the complement clause) tend to be of secondary discourse prominence.

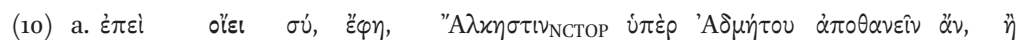

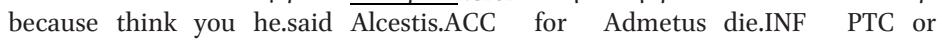

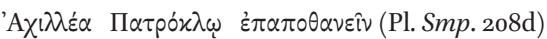

Achilles Patroclus die.after.INF

Do you really think, he said, that Alcestis would have died for Admetus or that Achilles would have died after Patroclus (...).

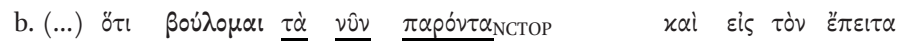
that I.want the now be.present.PTCP.ACC also to the thereafter

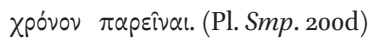

time be.present.INF

(...) that I want the things I have now to be mine in the future as well.

18) Translations of Plato's Symposium (sometimes adapted) are taken from Nehamas and Woodruff (Cooper 1997).

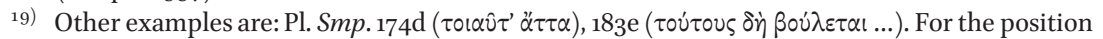
of oîंos in the clause, see Allan, Forthc. 


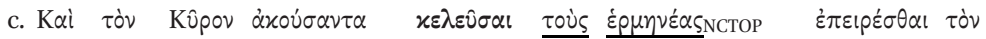
And ART Cyrus having.heard order.INF the interpreters.ACC ask.INF ART

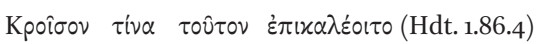

Croesus who that invoke.OPT.3.SG

And Cyrus heard it and ordered the interpreters to ask Croesus who he was invoking.

d. [Aristodicus stopped the Cymaeans from surrendering Pactyes]

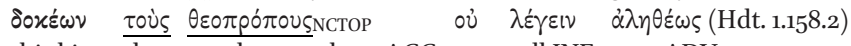

thinking the oracle.consulters.ACC not tell.INF true.ADV

(...) thinking that those who had consulted the oracle were not telling the truth.

In none of these cases the clausal topic refers to a central, persisting actor in the discourse. In (a), Alcestis is merely mentioned in passing as one of a series of examples of self-sacrifice. In (b), $\tau \dot{\alpha} \nu \hat{v} \nu \pi \alpha \rho o ́ v \tau \alpha$ is an inanimate entity of passing interest to the interlocutors' discourse. The anonymous interpreters and messengers to the oracle in (c) and (d) are peripheral participants in the action leaving the stage immediately after their entry. ${ }^{20}$ Note that the main (embedding) verb may also be an infinitive ( $\varkappa \varepsilon \lambda \varepsilon \hat{v} \sigma \alpha \iota$ in c) or a participle ( $\delta \circ \varkappa \varepsilon ́ \omega \nu$ in d).

\section{Preposed Focus}

The focus of a sentence is that piece of information 'which is relatively the most important or salient in the given communicative setting, and considered by $\mathrm{S}$ [peaker] to be most essential for $\mathrm{A}$ [ddressee] to integrate into his pragmatic information' (Dik 1997: I.326). It is 'the element of information whereby the presupposition and the assertion DIFFER from each other. The focus is that portion of an utterance which cannot be taken for granted at the time of speech.' (Lambrecht 1994: 207). To explain the preposing of narrow focus constituents, I would like to suggest that the preposed position is a way to mark the constituent at issue as highly focal. Typically, the preposed narrow focus constituent is contrastive or counter-presuppositional.

As Dik's definition of focus as the piece of information 'which is relatively [my italics, $R J A$ ] the most important or salient' makes clear, it is possible to conceive of focality as a scalar rather than a discrete notion. A piece of information can be more focal than another and this difference can be coded by different grammatical constructions. As Givón (2001: II.221) notes with regard to contrastive focus constructions, 'the notion of contrast is neither grammatically nor cognitively discrete. Rather, it rests upon the more fundamental cognitive dimensions of informational predictability and its converse, counter-expectancy, both

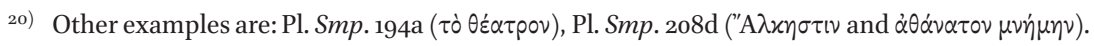


of which are at least in principle scalar. While grammatical constructions do not code promiscuously-many points along a functional-cognitive scalar domain, they do often code more than a single binary split.'

Contrastive foci show a high degree of focality because they involve chunks of information which are relatively unpredictable due to the presence of a salient alternative piece of information. This alternative piece of information may be expressed in the form of a corresponding constituent in a parallel construction $^{21}$ or it involves information which the speaker presupposes to be entertained by the addressee (counter-presuppositional focus, see Dik 1997: I.332). Dik distinguishes a number of subtypes of counter-presuppositional foci, e.g. (i.) rejecting focus, e.g. A: - John bought apples. B: - No, he didn't buy APPLES. (ii.) replacing focus, e.g. A: - John bought apples. B: - No, he bought BANANAS. (iii.) expanding focus, e.g. John grows bananas. B: - He also SELLS them. (iv.) restricting focus, e.g. John grows and sell potatoes. B: - No, he only SELLS them. (v.) selecting focus, e.g. A: - Are you going to rent or buy a car? B: - I'm going to BUY one. ${ }^{22}$

Now consider the following examples of preposed focal constituents.

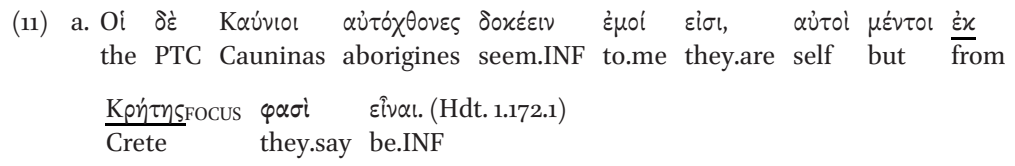

I think the Caunians are aborigines of the soil, but they say themselves that they came from Crete.

b. [Astyages asks the cowherd who had given him the boy.]

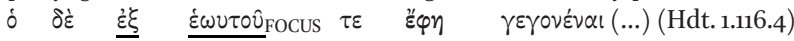

he PTC from himself PTC he.said be.born.PRF.INF

He [the cowherd] said that he [Cyrus] was his own son (...).

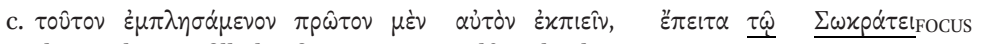
that having.filled first PTC self drink.INF next $\overrightarrow{A R T} \overline{\text { Socrates }}$

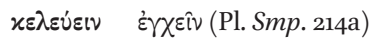

order.INF pour.in.INF

This he [Alcibiades] got filled to the brim, he drained it himself and then ordered them to fill it up for Socrates.

\footnotetext{
21) An example of this type of contrastive focus is: Socrates and Plato came to see me. SOCRATES was NICE, but PLATO was BORING. Here, SOCRATES and PLATO are contrastive topics, while NICE and BORING are contrastive foci (see also Hengeveld \& Mackenzie 2008, 97).

22) For this typology of focus types, I refer to S. Dik 1997: I.331-333. See also H. Dik 1995: 38-39.
} 


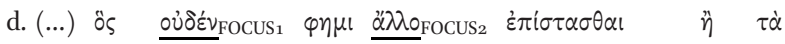

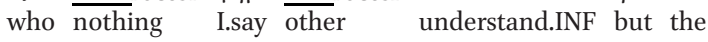

غे $\omega \tau \iota \ltimes \alpha \dot{\alpha}(\mathrm{Pl}$. Smp. 177e)

art.of.love

(...) when I say I understand nothing else but the art of love.

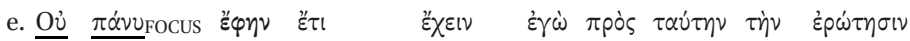

$\overline{\text { not }} \overline{\text { quite }}$ I.said any.more can.INF I to that ART question

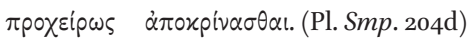

ready.ADV answer.INF

I said that I could in no way give a ready answer to that question.

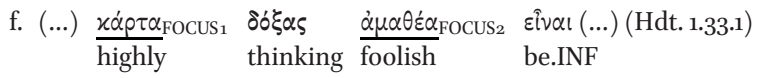

(...) thinking him a great fool (...)

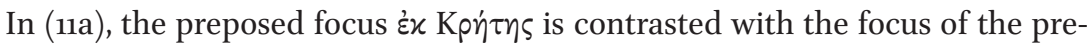

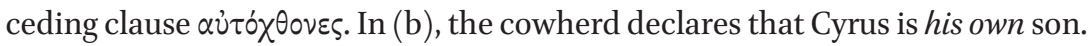
The focus $\dot{\xi} \xi \dot{\varepsilon} \omega v \tau 0 \hat{v}$ is counter-presuppositional: it replaces Astyages' presupposition that Cyrus is not the cowherd's son (replacing focus in Simon Dik's

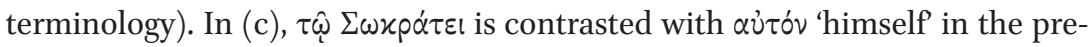
ceding clause (cf. also $\pi \rho \hat{\omega} \tau o v \mu \dot{\varepsilon} \nu$..., है $\pi \varepsilon \tau \alpha \alpha$...). Examples (d) and (e) contain a negation (cf. Dik's rejecting focus: the speaker rejects a proposition of which (s)he presumes that it is entertained by the addressee). In (d), there is a hyper-

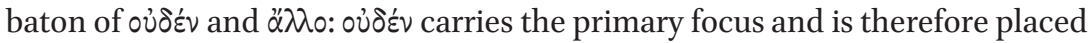
before the main verb; $\alpha \lambda_{0}$ has less focus and is located within the complement clause before the infinitive. ${ }^{23}$ Together, they constitute the direct object of the infinitive complement $\dot{\tau} \pi \dot{i} \sigma \alpha \sigma \theta \alpha$ l. O $\tau^{\prime} \alpha \nu v$ in (e) has scope over the infinitive complement. The main verb $\varepsilon^{\prime} \varphi \eta \nu$ is outside the scope of negation. ${ }^{24}$ The intensifying adverb $x \alpha \dot{\rho} \tau \alpha$ in (f) is as modifier of the adjective $\alpha \mu \alpha \theta \varepsilon \dot{\varepsilon} \alpha$ and is placed

23) Preposed negations seem to occur more frequently than non-preposed negations. In my data, there are 9 instances of preposed negations against 4 non-preposed. In 3 of these 4 instances, the non-preposed negation occurs in a coordinated complement clause: $\varphi \dot{\alpha} \varsigma_{S A Y . P T C P}(. ..) \circ \dot{u} \varkappa_{\text {NEG }}(\ldots)$

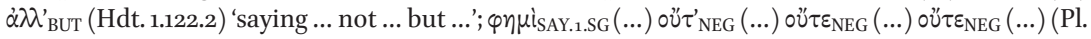

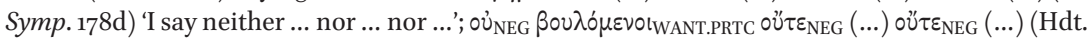
1.160.1) 'wanting neither ... nor ...' (with one preposed and two coordinated non-preposed negations). The only remaining case of a non-preposed negation (Hdt. 1.158.2) is difficult to explain.

24) Note that when ov immediately precedes the main verb (such as $\chi \varepsilon \lambda \varepsilon v i \omega$, olo $\mu \alpha l, \varphi \eta \mu i)$ ), it is often ambiguous as to whether it has scope over the main verb or is in fact semantically associated with the embedded infinitive (see Kühner-Gerth 1898: II.18oA3; Wackernagel 1926: 262; SchwyzerDebrunner 1950: 593), a phenomenon referred to as 'negative raising', e.g. o ${ }_{\mathrm{NEG}} \varphi \eta \sigma \nu_{3 . S G} \delta \dot{\omega} \sigma \varepsilon \nu_{\mathrm{INF}}$ 'he says he will not give'. 
before the main verb to provide extra emphasis (primary focus), $\alpha \mu \alpha \theta \varepsilon \dot{\varepsilon} \alpha$ is part of the complement clause and carries secondary focus (because located before infinitive). ${ }^{25}$

Non-preposed narrow focus constituents tend to be non-contrastive and non-counter-presuppositional. Typically, non-preposed foci are what Simon Dik calls completive, that is to say, they serve to fill in a specific piece of information for which the speaker presumes that the addressee has an information gap, e.g. A: - What happened yesterday? B: - Socrates met with Protagoras. The information provided by the focus constituent neither counters any presupposition nor does it stand in contrast to another focal constituent. It merely adds an element to the shared common ground of speaker and addressee. Since they do not involve a contrast with an alternative piece of information which is explicitly mentioned or presupposed, completive focus constituents do not show a high degree of focality. For this reason, as I would suggest, such focus constituents tend not to receive the marked position preceding the main verb. Because we are still dealing with a narrow focus rather than with a broad focus the constituent at issue is located in the slot preceding the complement infinitive.

(12) a. [Alyattes sent a herald]

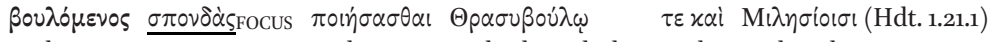
wishing truce make.INF with.Thrasybulus and with.Milesians (...) wishing to make a truce with Thrasybulus and the Milesians.

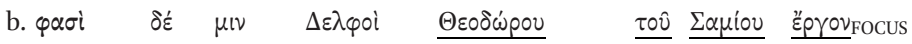
they.say. PRT it.ACC Delphians Theodorus.GEN the Samian work

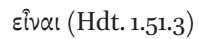

be.INF

The Delphians say that it is the work of Theodorus of Samos.

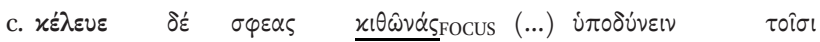
order.IMP PRT they.ACC tunics wear.under.INF the

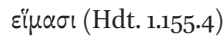

cloaks

And order them to wear tunics under their cloaks.

\footnotetext{
25) A more trivial observation is that also interrogative pronouns (carrying questioning focus [Dik 1997: I.331-333]) are preferably placed in sentence-initial position (Kühner-Gerth 1898: II.515) and

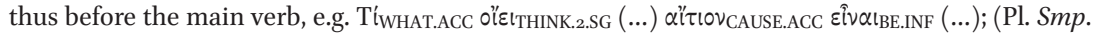
207a) 'What do you suppose to be the cause (...)?'. Although clause-initial position is not obligatory in Ancient Greek, exceptions are infrequent (see Bertrand 2010, 333-338). In my data, there are five instances of interrogative pronouns in preposed position against no instances of non-preposed position.
} 


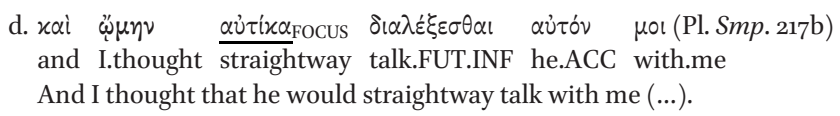

In these cases, the constituent preceding the embedded infinitive provides the most important piece of new information without salient contrast or counterpresuppositionality being involved. The infinitives in (12a)-(12c) are verbs with an unspecific lexical meaning providing little salient new information ('make', 'be', 'wear'). In (12d), it is to be expected that Socrates, upon meeting him, would speak to Alcibiades. The infinitive $\delta\left\llcorner\alpha \lambda \xi^{\prime} \xi \varepsilon \theta \alpha\right.$ l can therefore be considered presupposed information. The adverb $\alpha$ vix $\alpha$ provides the most salient new information in the infinitive clause.

\section{Preposed Infinitive}

The next issue I would like to go into relates to preposed infinitives. This marked word order can be accounted for by the same word order schema as the one discussed above. In the case of preposed infininitives, it is the infinitive (clause) which fills the special focus slot preceding the main verb. An important additional condition for preposing the infinitive is that the infinitival complement clause is short. Preferably, it only consists of the infinitive itself, possibly accompanied by one other constituent (rarely more). The effect of preposing the infinitive is to give focus to the infinitive. Often, the infinitive is contrastive with another infinitive in the context. E.g.,

(13) a. [Astyages asked Harpagus if he knew what kind of meat he had eaten.]

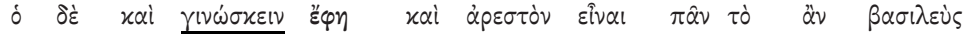
he PTC and know.INF he.said and pleasing be.INF all what PTC king

हैpon (Hdt. 1.119.7)

do.SBJV.3.SG

He said that he knew and that all the king does is pleasing.

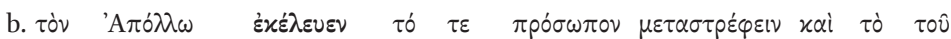
ART Apollo.ACC he.ordered the PTC face turn.INF and the of.the

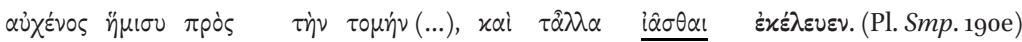
neck half towards the wound and the.rest heal.INF he.ordered

He [Zeus] ordered Apollo to turn its face and half-neck towards the wound (...) and he commanded him to heal the rest.

c. [Alcibiades:]

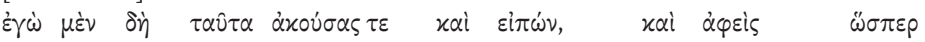

I PTC PTC that having.heard and having.said and having.sent like

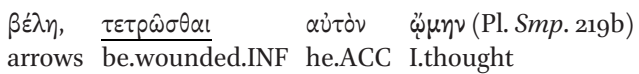

His words made me think that my own finally hit the mark, that he was smitten by my arrows. 


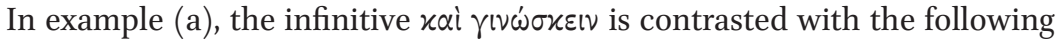

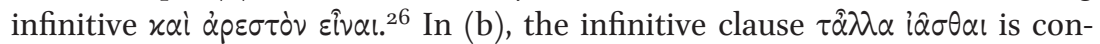

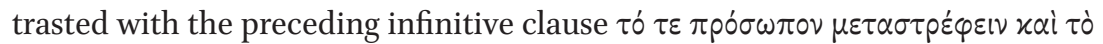

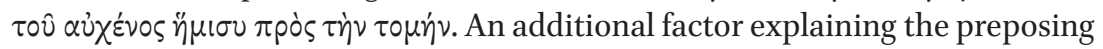
of the infinitive may be that $\dot{\varepsilon} x \varepsilon \dot{\lambda} \varepsilon v \varepsilon v$ is merely repeated and thus not very informative. The infinitive $\tau \varepsilon \tau \rho \hat{\omega} \sigma \theta \alpha \mathrm{l}$ in (c) does not contrast explicitly with another verb. However, it does stand in contrast with the content of the following section in which Socrates turns out to be unaffected by Alcibiades efforts. Alcibiades thought Socrates was 'wounded' indeed but, in actual fact, Socrates was to turn him down.

In other cases, the preposed infinitival clause appears to be used to highlight an unexpected, counter-presuppositional or otherwise especially newsworthy event.

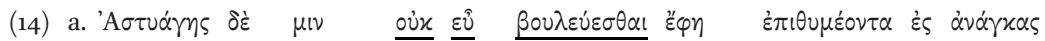
Astyages PTC he.ACC $\overline{\text { not }} \overline{\text { well }} \overline{\text { resolve.INF }}$ he.said wishing in torture

$\mu \varepsilon \gamma \dot{\alpha} \lambda \alpha \varsigma \dot{\alpha} \pi \iota \varkappa \varepsilon \varepsilon \varepsilon \sigma \theta \alpha l$ (Hdt. 1.116.4)

great arrive.INF

Astyages said that he was not well advised if he wished to find himself in a desperate situation.

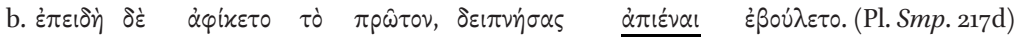
when PTC he.came the First having.dined leave.INF he.wanted The first time he came, he wanted to leave after dinner.

c. [Agathon:]

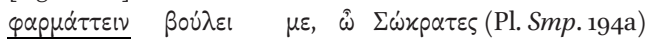

$\overline{\text { bewitch.INF }}$ you.want me o Socrates

You want to bewitch me, Socrates.

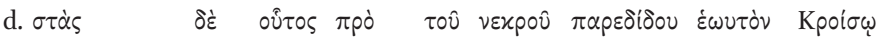

having.stood PTC he before the corpse gave.up himself to.Croesus

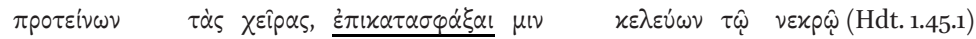
stretching.out the hands kill.on.INF he.ACC telling the corpse

$\mathrm{He}$ [Adrastus] stood before the body and gave himself up to Croesus, stretching out his hands and telling him to kill him over the corpse.

26) This construction is very typical of coordinated focus constituents: one member of the set is placed preverbally while the other member(s) follow(s) the verb. Other examples from my

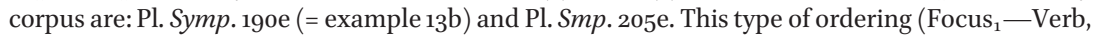
Focus $_{2}$, etc.) is a manifestation of the 'one chunk per clause principle' (Givón 2001: II.222-223), which states that preferably only one portion per clause should fall under the scope of asserted new information. To avoid a heavy clustering of focus constituents, the information load is spread over two (or more) information units. The first information chunk contains the verb; the following chunk(s) only consist of a focal constituent. For chunking-phenomena in Ancient Greek, see also Slings 1997, 2002. 
Astyages in (a) contradicts the idea he presumes to be held by the cowherd

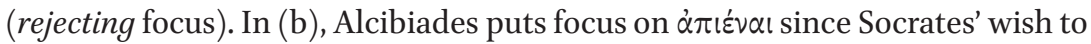
leave comes as a great surprise: it contradicts Alcibiades' expectation that he would stay (replacive focus). In (c), Socrates has been praising Agathon excessively. Agathon, however, corrects the presupposition (replacive focus) that this praise is favorable to him by pointing out that Socrates is actually casting a spell on him (the implicit idea behind this is that receiving too much praise may incur the jealousy of the gods [Dover 1980]). ${ }^{27}$ Adrastus in (d) expresses the remarkable request to be killed by Croesus on Atys' body (who had been killed by Adrastus). The extraordinary and unexpected character of Adrastus' wish is marked by preposing the infinitive $\varepsilon \pi \iota \alpha \tau \alpha \sigma \varphi \alpha^{\prime} \xi \alpha l$ 'to be killed on'. Its dative complement $\tau \hat{\omega}$ vExp$\hat{\omega}$ is placed after the verb because it is provides informa-

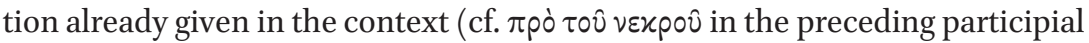
clause).

\section{Preposed Theme and Clausal Setting}

Hitherto, I have discussed what is perhaps the most notable feature of word order in complex sentences: the placement of topical and focal constituents semantically belonging to the complement clause in the topic and focus slots of the main verb. In the following section, the position of the extra-clausal constituents Themes and clausal Settings within the complex sentence will be dealt with. A Theme is a left-detached extra-clausal constituent, typically serving to (re)establish a topic in the discourse by bringing the referent back into the centre of attention. Settings are adverbial clauses preceding the (main) clause specifying time, location and/or other circumstantial state of affairs. Themes and Setting clauses are often combined. For example,

(15) [Description of the Persian army and fleet]

$[\Xi \dot{\varepsilon} \rho \xi \eta \varsigma$
Xerxes PTC $\delta \dot{\varepsilon}$ THEME

Theme $\Xi \dot{\varepsilon} \rho \xi \eta \varsigma$ resumes the narrative revolving around the discourse topic Xerxes. The preceding section contains an extensive description of the Persian army and fleet which was rounded off with a digression on Artemisia of 27) Note the position of the postpositive pronoun $\mu \varepsilon$ attached to the main verb (for this phe-
nomenon, see note 15). 
Halicarnassus, one of the commanders of the fleet. The function of the Setting clause is typical: it creates both an anaphoric link to the preceding discourse, the description of the army, as well as providing a background to the subsequent discourse unit.

Although there are only few examples in my corpus, Themes appear to be located before the main verb even if they are semantically and syntacticallynote the accusative case in the example below-associated with the complement clause. I only found two examples in my data. In both cases, the Theme precedes an interrogative pronoun.

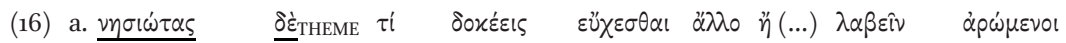

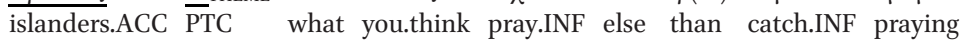

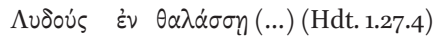

Lydians at sea

As for the islanders, what more do you think they pray for than (...) to catch Lydians at sea $(\ldots)$ ?

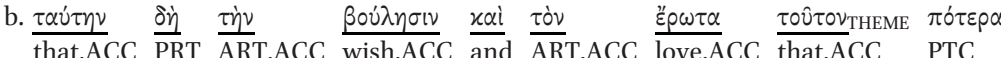

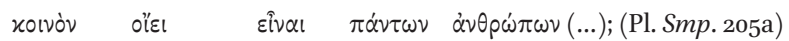

common you.think be.INF all.GEN people.GEN

As for this wish and this love, do you suppose them to be common to all mankind (...)?

These constituents are not clause-internal topics but extra-clausal (i.e. left detached) Themes. In Ancient Greek, there are indications that constituents preceding the interrogative pronoun constitute separate intonation units. Clitic particles such as $\alpha v$ and unaccented personal and indefinite pronouns are placed after the interrogative pronoun (Marshall 1987, 19), which points to an intonation boundary preceding the interrogative pronoun. ${ }^{28}$ For example,

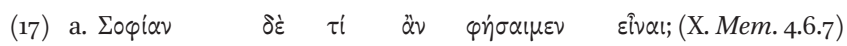

wisdom.ACC PTC what PTC say.OPT.1.pl be.INF

And what of Wisdom? How shall we describe it? ${ }^{29}$

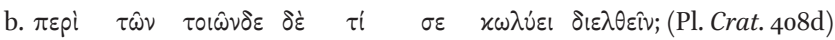

about ART these PTC what you keeps discuss.INF

But what keeps you from discussing these gods?

The position of $\alpha \nu$ in (a.) and $\sigma \varepsilon$ in (b.) demonstrate that the interrogative pronoun is preceded by an intonational boundary. ${ }^{30}$ The left-detached status

\footnotetext{
28) For the 'delayed position' of clitic particles as evidence for intonation unit boundaries ('colonformation'), I refer to Fränkel 1964, Marshall 1987, Ruijgh 1990 and Goldstein 2010.

29) Translation Marchant (Marchant \& Todd 1923).

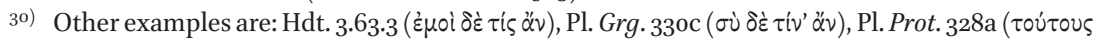


of $\sigma \circ \varphi i \alpha \nu$ and $\pi \varepsilon p i \tau \hat{\omega} \nu \tau 0\llcorner\hat{\omega} \nu \delta \varepsilon$ shows that these constituents are extra-clausal Themes rather than clause-internal topics. ${ }^{31}$ Accusative-marking is not problematic for assuming a Theme status. In Ancient Greek, Themes can appear in oblique cases (Slings 1997, Bertrand 2010). This phenomenon is also known from other languages (Dik 1997: II.391-392), e.g. German Diesen Film, den sah ich als ich ein Kind war (from Lambrecht 2001: 1052), where the Theme construction shows accusative case-marking.

Unlike Themes, Setting clauses that are associated with the complement clause are placed after the main verb but preceding the infinitival complement clause.

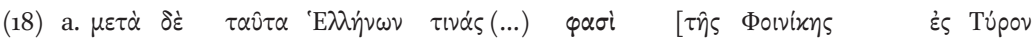
after PTC that of.Greeks some.ACC they.say ART Phoenicia.GEN at Tyre

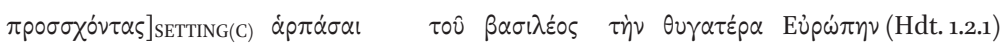
having.landed carry.off.INF the king.GEN the daughter Europa

They say that following these events some Greeks landed at Tyre in Phoenicia and carried off the king's daughter Europa.

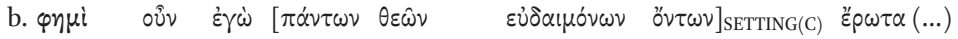
say.1.SG then I all.GEN gods.GEN happy.GEN being.GEN Love.ACC

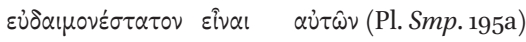

happiest be.INF of.them

I maintain, then, that while all the gods are happy, Love (...) is the happiest of them all.

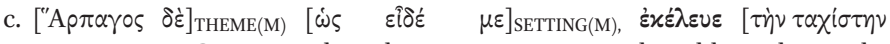
Harpagus PTC when he.saw me he.told in.the.quickest.way

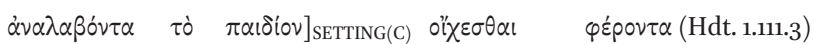
having.taken the child go.away.INF bringing

And Harpagus, when he saw me, he told me to take the child with all speed and bring it away (...).

The Setting in (a) is a conjunct participle clause modifying the subject accusative 'E $\lambda \eta \nu^{\prime} \omega \nu \tau \iota \nu \alpha$ s. In (b), the Setting is an absolute genitive clause. ${ }^{32}$ Example (c) contains a Theme $(\mathrm{M})$ and a Setting $(\mathrm{M})$ preceding the main clause, as well as a Setting $(\mathrm{C})$ preceding the complement clause.

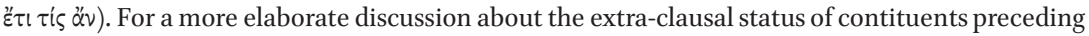
the interrogative pronoun, see Bertrand 2010, 337.

31) The absence of resumptive pronouns is not a conclusive indication of clause-internal status of these constituents given that the zero-anaphora is the normal way in Ancient Greek to refer to highly accessible discourse topics.

32) The personal pronoun $\varepsilon \gamma \hat{\jmath}$ here functions as an unemphatic given topic and is therefore placed after the verb. For غ̇ү $\dot{\omega}$ and $\sigma \dot{v}$ as unemphatic postpositives, see Dik 2003. The position of given topics in complex sentences will be discussed later.
} 


\section{Setting Adverbs and Given Topics}

The final issue I would like to address is the placement of adverbs with Setting function and given topics. In the preceding section, the position of clauses with Setting function was dealt with. Besides clauses, also adverbs (or adverbial phrases) can function as Settings. Setting adverbs are sentence adverbs providing a semantic frame with respect to which the state of affairs described in the subsequent sentence or discourse segment is to be assessed.33 Setting adverbs are placed in clause-initial position preceding new or contrastive topics (though after conjunctions and relative pronouns). They typically have a spatio-temporal or discourse-structural meaning, e.g. हi $\tau \alpha /$ है $\pi \varepsilon เ \tau \alpha$ 'then, there-

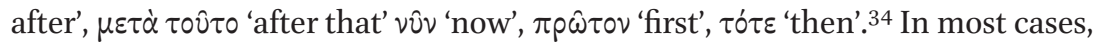
Setting adverbs were probably not separated from the clause by an intonation boundary but there are cases which show signs of a left-detached, extra-clausal

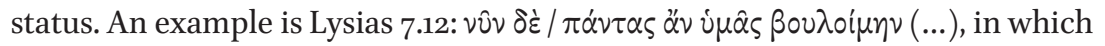
the delayed position of $\alpha \dot{\alpha}$ can be seen as an indication of an intonation boundary after vôv.

In complex sentences, frame-setting adverbs show a strong tendency to be placed in initial position even if they semantically belong to the complement clause. Examples from my corpus are the following:

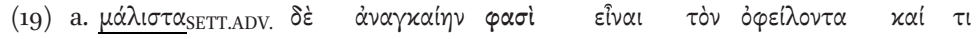 particularly PTC inevitable they.say be.INF the debtor.ACC also some

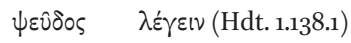 falsehood speak.INF

In particular, they say that it is inevitable that the debtor also speaks some falsehood.
b.
next ART for.Socrates order.INF pour.in.INF
(...) then he ordered them to fill it up again for Socrates.

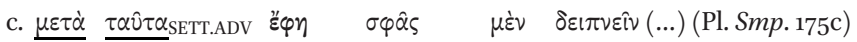 after that he.said they.ACC PTC dine.INF He said that, after that, they started eating (...)

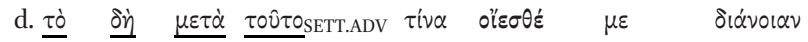 $\overline{\text { ART }} \overline{\text { PTC }} \overline{\text { after that what you.think me.ACC state.of.mind }}$

After that, what state of mind do you think I had?

\footnotetext{
33) For the frame-setting function of sentence-initial adverbials, I refer to Chafe 1984.

34) Possibly also modal/attitudinal adverbs can function as frame-setting adverbs in Ancient Greek. The epistemic adverbs ' $\sigma \omega \varsigma$ 'perhaps' and $\pi \alpha \dot{\nu} \tau \omega \varsigma$ 'by all means, certainly', for example, show a strong tendency to occur at the beginning of the clause.
} 
In examples (a) and (b [=11c]), the adverb modifies the main clause; in (c)

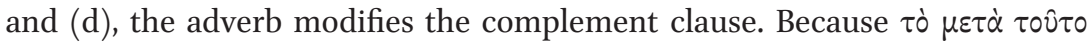
in (d) is ambiguous between an adverb and a noun (being a substantivized prepositional phrase), it can also be analyzed as a Theme: 'as for the time after that, what state of mind do you think I had?'.

In Ancient Greek, given topics are placed in the position immediately following the verb. ${ }^{35}$ Given topics refer to entities which are currently in the centre of attention and therefore assumed by the speaker to be highly accessible to the addressee. Given topics do not stand in any significant contrast with alternative topical referents.

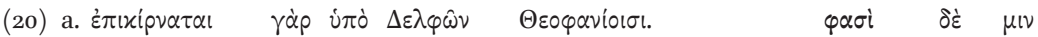
is.being.mixed for by Delphians at.the.Divine.Appearance they.say. PRT it.ACC

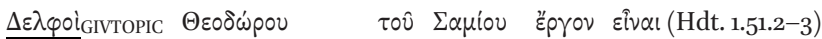

Delphians Theodorus.GEN the Samian work be.INF

For it is used as a mixing-bowl by the Delphians at the feast of the Divine Appearance. The Delphians say that it is the work of Theodorus of Samos.

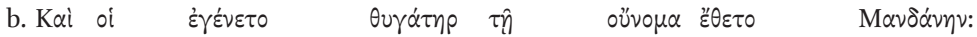
and to.him had.been.born daughter to.whom name had.been.set Mandane

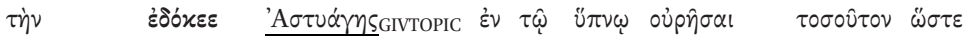
REL.F.ACC dreamed Astyages in the sleep urinate.INF so.much that

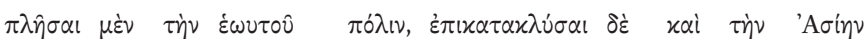
fill.INF PTC the of.himself city flood.INF and also ART Asia

$\pi \hat{\sigma} \sigma \alpha v$. (Hdt. 1.107.1)

all

Astyages had a daughter, whom he called Mandane: he dreamed that she urinated so much that she filled his city and flooded all of Asia.

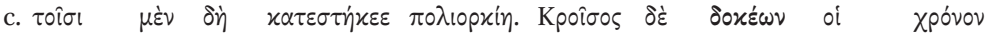
to.them PRT PRT had.begun siege Croesus PTC thinking to.him time

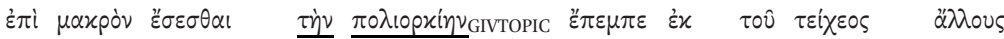
till long be.FUT.INF the hiege hent from the walled.city other

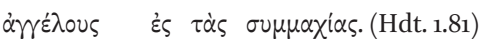

messengers to the allies

So the siege had begun. But Croesus, supposing that the siege would last a long time, again sent messengers from the city to his allies.

35) The idea that given topics are located in a position immediately following the verb I owe to Matić 2003 (who calls them continuous topics). See also Allan, Forthc. 


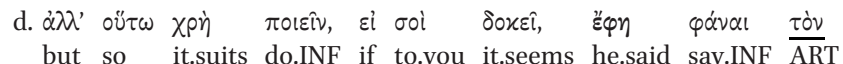

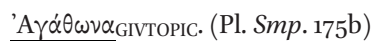

Agathon

'Well all right, if you really think so,' he [Aristodemus] said that Agathon said.

In examples (a) and (b), $\Delta \varepsilon \lambda \varphi \circ i$ and 'A $\sigma \tau u \alpha \gamma \eta \varsigma$ are the grammatical subjects of the main verb. Since they are given topics, they are placed directly after the main verb. ${ }^{36}$ They are highly accessible referents since they have been mentioned in the preceding sentence. In (a) the Delphians are referred to as passive agents $i \pi \dot{o} \Delta \varepsilon \lambda \varphi \hat{\omega} v$. In (b) Astyages is referred to by the dative pronoun oi. The accusative $\tau \dot{\eta} \nu \pi 0 \lambda$ เopxinv (c) and $\tau \dot{\partial} \nu$ 'A $\gamma \alpha \dot{\alpha} \theta \omega \nu \alpha$ in (d) are the subjects

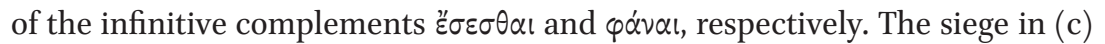
is already mentioned in the preceding sentence as grammatical subject and is therefore highly accessible. ${ }^{37}$ In example (d), Aristodemus is speaking about the conversation he had with Agathon about whether they should bring in Socrates or leave him standing in the neighbor's porch. As he is one of the current interlocutors, Agathon is a given discourse topic.

\section{Raising}

The preposing of constituents which semantically belong to the complement clause can be regarded as a specific form of raising. More specifically, it is a form of what Dik calls 'Raising-1' which he describes as: 'a form of pure displacement: the term in question appears in the matrix clause, but further remains unaffected: it retains its form appropriate to its function in the embedded domain' (Dik, 1997: II.344). As I have argued, in Ancient Greek this specific type of raising is triggered by pragmatic factors. It appears that there are no grammatical constraints to the process. All constituents of the complement clause are potentially available for preposing, regardless of their syntactic or semantic properties. A very similar type of pragmatically motivated raising is found in Hungarian, as is illustrated by the following examples (from De Groot 1981: 47, 52; see also Hengeveld \& Mackenzie 2008: $368-369) \cdot{ }^{38}$

\footnotetext{
36) The clitic pronoun $\mu \iota v$ is in Wackernagel's position and can therefore be disregarded.

37) The non-second position of the clitic oi after the embedding verb $\delta \circ x \varepsilon \dot{\varepsilon} \omega \nu$ should not be regarded as irregular. In complex sentences, the most frequently occurring position of postpositive pronouns is in fact directly behind the main verb. This also means that the delayed position of oi cannot be taken as a conclusive indication of an intonation boundary preceding $\delta \circ x \varepsilon \dot{\varepsilon} \omega$.

38) A similar pragmatically motivated form of clause intertwining is also found in Latin (Bolkestein 1981).
} 
(21) a. [János $]_{\text {Top }}[\mathrm{azt}]_{\mathrm{Foc}}$ mondta, hogy $[\mathrm{a} \text { taxi }]_{\text {Top }}[\ddot{t} \text {-re }]_{\text {Foc }}$ jöjjön John DEM said that the taxi at.five come John said that the taxi would come at five.

b. [János $]_{\text {Top }}[\text { öt-re }]_{\text {Foc }}$ mondta, hogy $[\mathrm{a} \text { taxi }]_{\text {Top }}$ jöjjön John at.five said that the taxi come John said that the taxi would come at five.

c. $[\text { Mari }]_{\text {Top }}[\text { nem }]_{\text {Foc }}$ hiszem, hogy ismeri Chomskyt Mary.NOM not believe.I that knows.she Chomsky.ACC I do not believe that Mary knows Chomsky.

Hungarian basic word order is similar to Ancient Greek in that topical elements are placed in clause-initial position, while narrow focus constituents are in preverbal position. Another relevant feature of Hungarian is the presence of a cataphoric demonstrative element azt which refers to the subsequent complement clause. This demonstrative azt occupies the preverbal focus position of the main clause indicating that the complement clause as a whole is focal information. The preverbal focus position in the complement clause is occupied by ötre 'at five'. In (21b), ötre is preposed in the preverbal focus position of the main clause. In (21c), the topic of the complement clause Mari (note the nominative case-marking) is placed in the topic position of the main clause.

\section{Conclusion}

I have argued that placing constituents of the complement clause in a position preceding the main verb serves the purpose of pragmatically highlighting these constituents. Constituents which can be placed in this pragmatically marked preposed position are Themes, topics, narrow foci and adverbs with Setting function. The infinitive complement clause can also be preposed in order to mark it as a narrow focus. The structural Theme, topic and focus position in the main clause are 'borrowed', so to speak, by constituents of the complement clause in order to increase their discourse prominence. The general word order schema of complex sentences as represented in schema (5) can be characterized roughly as a combination of two intertwined clausal word order schemas. This paper is intended as a first attempt to analyse constituent-preposing in complex sentences. No doubt, further research will reveal additional factors which trigger clause-intertwining in Ancient Greek. 


\section{References}

Allan, Rutger J., Forthc. Changing the Topic: Topic Position in Ancient Greek Word Order. Mnemosyne.

Bertrand, Nicolas. 2010. L'ordre des mots chez Homère: Structure informationelle, localisation et progression du récit. Unpublished Diss. University of Paris-Sorbonne.

Bolkestein, A. Machtelt. 1981. Embedded predications, displacement and pseudo-argument formation in Latin. In A.M. Bolkestein et al., Predication and expression in functional grammar, 63-112. London: Academic Press.

Chafe, Wallace L. 1984. How people use adverbial clauses. In: Claudia Brugman \& Monica Macaulay (eds.). Proceedings of the Tenth Annual Meeting of the Berkeley Linguistics Society, 437459 .

Chafe, Wallace L. 1994, Discourse, consciousness, and time: The flow and displacement of conscious experience in speaking and writing, Chicago/London: The University of Chicago Press.

Chanet, A.-M. 1988. Objet propositionnel, prolepse et objet externe. In: A. Rijksbaron, H.A. Mulder \& G.C. Wakker (eds.), In the footsteps of Raphael Kühner: Proceedings of the international colloquium in commemoration of the 15oth anniversary of the publication of Raphael Kühner's Ausführliche Grammatik der griechischen Sprache, II. Theil, Syntax. Amsterdam: J.C. Gieben, 67-97.

Cooper, John M. (ed.). 1997, Plato: Complete Works, Indianapolis/Cambridge: Hackett.

De Groot, Casper. 1981. Sentence intertwining in Hungarian. In: A.M. Bolkestein et al., Predication and Expression in Functional Grammar. London: Academic Press, 41-62.

Devine, Andrew M. \& Laurence D. Stephens. 2000. Discontinuous syntax. Hyperbaton in Greek. Oxford: Oxford University Press.

Dik, Helma. 1995. Word order in Ancient Greek: A pragmatic account of word order variation in Herodotus. Amsterdam: Gieben.

Dik, Helma. 2003. On unemphatic 'emphatic' pronouns in Greek: Nominative pronouns in Plato and Sophocles. Mnemosyne 56: 535-550.

Dik, Helma. 2007. Word order in Greek tragic dialogue. Oxford: Oxford University Press.

Dik, Simon C. 1997. The theory offunctional grammar, 2 Vols. Berlin/New York: Mouton de Gruyter.

Dover, Kenneth J. 1960. Greek word order. Cambridge: Cambridge University Press.

Dover, Kenneth J. 1980. Plato: Symposium. Cambridge: Cambridge University Press.

Firbas, Jan. 1964. On defining the theme in functional sentence analysis. Travaux Linguistiques de Prague 1: 267-280.

Fränkel, Eduard. 1964. Kolon und Satz: Beobachtungen zur Gliederung des antiken Satzes; Kolon und Satz, II; Nachträge zu 'Kolon und Satz'. In: Kleine Beiträge I. Zur Sprache, Rome, 73-139.

Givón, Talmy. 1983. Topic continuity in discourse: A quantitative cross-language study, Amsterdam/Berlin: John Benjamins.

Givón, Talmy, 2001, Syntax, 2 Vols. Amsterdam/Philadelphia:John Benjamins.

Godley, A.D. 1920. Herodotus, 4 Vols. Cambridge, MA: Harvard University Press.

Goldstein, David M. 2010. Wackernagel's law in fifth-century Greek, Unpublished Diss. University of California, Berkeley.

Halliday, Michael A.K. 1967. Notes on transitivity and theme in English. Journal of Linguistics 3: 199-244.

Hengeveld, Kees \& J. Lachlan Mackenzie. 2008. Functional discourse grammar: A typology-based theory of language structure, Oxford: Oxford University Press.

Kühner, Rafael \& Bernhard Gerth. 1898-1904. Ausführliche Grammatik der griechischen Sprache. Zweiter Teil; Satzlehre, 2 Vols. Hannover: Hahnsche Buchhandlung.

Lambrecht, Knut. 1994. Information structure and sentence form, Cambridge: Cambridge University Press. 
Lambrecht, Knut. 2001. Dislocation. In: Martin Haspelmath (ed.), Language typology and language universals: An international handbook, 1050-1078. Berlin: Mouton de Gruyter

Marshall, M.H.B. 1987. Verbs, nouns, and postpositives in Attic prose. Edinburgh: Scottish Academic Press.

Marchant, Edgar C., and Otis J. Todd. 1923. Xenophon, Memorabilia, Oeconomicus, Symposium, Apology. Cambridge, Mass./London: Harvard University Press.

Matić, Dejan. 2003. Topic, focus, and discourse structure: Ancient Greek word order. Studies in Language 27: 573-633.

Panhuis, Dirk. 1984. Prolepsis in Greek as a discourse strategy. Glotta 62: 26-39.

Ruijgh, Cornelis J. 1990. La place des enclitiques dans l'ordre des mots chez Homère d'après la loi de Wackernagel. In: H. Eichner \& H. Rix (eds.). Sprachwissenschaft und Philologie: Jacob Wackernagel und die Indogermanistik heute. Wiesbaden: Reichert, 213-233.

Schwyzer, Eduard and A. Debrunner. 1950. Griechische Grammatik, Zweiter Band, Syntax und syntaktische Stilistik. München: Beck.

Slings, Simon R. 1992. Written and spoken language: An exercise in the pragmatics of the Greek language. Classical Philology 87: 95-109.

Slings, Simon R. 1997. Figures of speech and their lookalikes: Two further exercises in the pragmatics of the Greek sentence. In: E.J. Bakker (ed.). Grammar as interpretation. Leiden/New York/Cologne: Brill, 169-214.

Slings, Simon R., 2002. Oral Strategies in the Language of Herodotus. In: Edgar J. Bakker, Irene J.F. de Jong, Hans van Wees (eds.). Brill's Companion to Herodotus, Leiden/Boston/Cologne: Brill, $53-77$.

Smyth, Herbert Weir, 1956, Greek Grammar. Revised by Gordon M. Messing, Harvard: Harvard University Press.

Wackernagel, Jacob W. 1892. Über ein Gesetz der indogermanischen Wortstellung. Indogermanische Forschungen. 1: 333-436.

Wackernagel, Jacob W. 1926. Vorlesungen über Syntax mit besonderer Berücksichtigung von Griechisch, Lateinisch und Deutsch. 2. Aufl., 2 Vols. Basel.

Wårvik, B. 2004. What is foregrounded in narrative? Hypotheses for the cognitive basis of foregrounding. In Tuija Virtanen (ed.). Approaches to cognition through text and discourse. Berlin/ New York: Mouton. 